\title{
Sex-specific evolution of bite performance in Liolaemus lizards (Iguania: Liolaemidae): the battle of the sexes
}

\author{
BIEKE VANHOOYDONCK ${ }^{1 *}$, FELIX B. CRUZ ${ }^{2}$, CRISTIAN S. ABDALA ${ }^{3}$, \\ DÉBORA L. MORENO AZÓCAR ${ }^{2}$, MARCELO F. BONINO ${ }^{2}$ and ANTHONY HERREL ${ }^{4}$ \\ ${ }^{1}$ Department of Biology, University of Antwerp, Universiteitsplein 1, B-2610 Wilrijk, Belgium \\ ${ }^{2}$ Instituto de Investigaciones en Biodiversidad y Medioambiente (INIBIOMA) CONICET-UNCOMA, \\ Bariloche, Argentina \\ ${ }^{3}$ Facultad de Ciencias Naturales e I.M. Lillo (UNT), Instituto de Herpetologia (FML), Tucumán, \\ Argentina \\ ${ }^{4}$ Musée National d'Histoire Naturelle, Paris, France
}

Received 19 March 2010; revised 6 May 2010; accepted for publication 6 May 2010

\begin{abstract}
Although differential selective pressures on males and females of the same species may result in sex-specific evolutionary trajectories, comparative studies of adaptive radiations have largely neglected within-species variation. In this study, we explore the potential effects of natural selection, sexual selection, or a combination of both, on bite performance in males and females of 19 species of Liolaemus lizards. More specifically, we study the evolution of bite performance, and compare evolutionary relationships between the variation in head morphology, bite performance, ecological variation and sexual dimorphism between males and females. Our results suggest that in male Liolaemus, the variation in bite force is at least partly explained by the variation in the degree of sexual dimorphism in head width (i.e. our estimate of the intensity of sexual selection), and neither bite force nor the morphological variables were correlated with diet (i.e. our proxy for natural selection). On the contrary, in females, the variation in bite force and head size can, to a certain extent, be explained by variation in diet. These results suggest that whereas in males, sexual selection seems to be operating on bite performance, in the case of females, natural selection seems to be the most likely and most important selective pressure driving the variation in head size. (C) 2010 The Linnean Society of London, Biological Journal of the Linnean Society, 2010, 101, $461-475$.
\end{abstract}

ADDITIONAL KEYWORDS: diet - ecomorphology - interspecific variation - natural selection - sexual differences - sexual selection.

\section{INTRODUCTION}

Phenotypic sexual differences can arise through, and be maintained by, different, non-mutually exclusive, evolutionary processes. Sexual selection, in which a trait is selected for because it confers a mating advantage in one of the sexes through its effect in intrasexual competition or mate choice, is the process that comes to mind first. However, competition for scarce resources (e.g. food) may also lead to niche divergence between the sexes, and associated phenotypic divergence through the process of natural selection (cf.

*Corresponding author. E-mail: bieke.vanhooydonck@ua.ac.be
Selander, 1966; Schoener, 1967). These different, in some cases even antagonistic, selective pressures on males and females may result in divergent evolutionary trajectories between the sexes.

Most studies linking phenotype with environment have largely neglected within-species variation. Instead the focus has been on a single sex, typically the male, or male and female data have been lumped together in trying to explain overall species-wide adaptive patterns. Only more recently have researchers begun to take sex-specific variation into consideration in comparative studies of adaptive radiations (Butler, 2007; Stuart-Fox \& Moussalli, 2007; Pincheira-Donoso et al., 2009). Surprisingly, these studies show that sexes often appear to be distinct ecological units, and differ in the way that variation in morphology and 
ecology relate to one another (Butler, 2007; Stuart-Fox \& Moussalli, 2007; Pincheira-Donoso et al., 2009).

To understand the evolutionary correlations between phenotypic divergence and ecological variation in either sex, quantification of the functional capacities at executing ecologically relevant tasks (i.e. performance; Huey \& Stevenson, 1979) is essential (Arnold, 1983). A plethora of studies have addressed whether and how natural selection shapes the ecomorphological relationship through the mediating effect on performance in a variety of animals (see the review in Irschick et al., 2008). Recently, researchers have begun to incorporate performance measures in sexualselection studies (Lailvaux et al., 2004, 2005; Huyghe et al., 2005; Lappin \& Husak, 2005; Lailvaux \& Irschick, 2006; Peterson \& Husak, 2006). However, disentangling the effect of natural selection and sexual selection on performance, and comparing it between males and females on a macroevolutionary (i.e. interspecific) scale, has, to our knowledge, received only little attention. In this paper we explore this issue and investigate the evolutionary processes responsible for the phenotypic divergence both among species and between sexes.

To do so, we study the evolution of bite performance in male and female Liolaemus lizards. We opt to quantify bite performance as it has previously been shown to be of prime importance in both natural- and sexual-selection contexts. For instance, whereas sexual differences in bite force have been linked to dietary divergence between males and females in different lizard species (Herrel et al., 1999, 2001a, 2006, 2008; Herrel, De Grauw \& Lemos-Espinal 2001b; Verwaijen, Van Damme \& Herrel, 2002; Brecko et al., 2008), in other lizards bite force has been shown to be important in determining the outcome of antagonistic interactions between males (Lailvaux et al., 2004; Huyghe et al., 2005), the acquisition of high-quality territories (Lappin \& Husak, 2005), and reproductive success (Husak, Lappin \& Van Den Bussche, 2009). Here, we combine estimates of sexual and natural selection and test which selective processes may influence the evolution of bite performance in males and females.

As a model system to investigate the (potentially divergent) evolutionary trajectories of bite performance in males and females, we used South American Liolaemus lizards. The genus Liolaemus is not only extremely speciose, comprising more than 200 species belonging to at least six clades (Schulte et al., 2000; Espinoza, Wiens \& Tracy, 2004; Pincheira-Donoso, Scolaro \& Sura, 2008), they are also very diverse with respect to ecological specializations and morphology, and are distributed over an extraordinarily large, for reptiles, environmental and geographic range (Espinoza et al., 2004; Schulte et al., 2004; Pincheira-
Donoso et al., 2009). Moreover, the degree of sexual dimorphism in body size, shape, home-range size, and/or coloration varies greatly among species (Rocha, 1999; Halloy \& Robles, 2002; Fox \& Shipman, 2003; Frutos, Camporro \& Avila, 2007; Pincheira-Donoso et al., 2009), suggesting a varying intensity of sexual selection (cf. Stuart-Fox \& Ord, 2004). However, despite their evolutionary success, liolaemids are an understudied group of lizards with regard to ecomorphological and evolutionary studies (Jaksić, Núñez \& Ojeda, 1980; Espinoza et al., 2004; Schulte et al., 2004; O'Grady et al., 2005; Pincheira-Donoso et al., 2009; Tulli et al., 2009).

Here, we aim to disentangle the effect of natural selection and sexual selection on the evolution of bite performance in Liolaemus lizards. As an estimate of the intensity of sexual selection, we use sexual dimorphism in head size. In lizards, sexual head size dimorphism has been used as an indirect measure of sexual selection, as heads are typically used as weapons in male combat, and as head size determines the outcome of direct physically aggressive encounters (e.g. Hews, 1990; Molina-Borja, Padron-Fumero \& Alfonso-Martin, 1998; Kratochvíl \& Frynta, 2002; Gvoždík \& Van Damme, 2003; Perry et al., 2004). To test the hypothesis that bite force is shaped by natural selection, we quantify the variation in diet, with prey items classified according to their functional properties (i.e. hardness and evasiveness), and relate it to the variation in bite capacity. More specifically, we test: (1) which head size variables explain the variation in (relative) bite force; (2) for a correlation between the variation in diet and head size; and (3) for a correlation between our measures of sexual and natural selection and (relative) bite force in males and females.

\section{MATERIAL AND METHODS}

\section{ANIMALS}

Individuals of 19 Liolaemus species were captured by noose or by hand, from 4 February to 17 February 2009, in central and southern Argentina. Species, the number of individuals (males and females) per species, and exact location of capture are given in Table 1. Animals were kept in cloth bags per species and location. All animals were transported back to the lab at the Instituto de investigaciones en biodiversidad y medioambiente (INIBIOMA) at Bariloche, Argentina. Every 5 days animals were released in a terrarium $(1.2 \mathrm{~m} \times 0.6 \mathrm{~m} \times 0.4 \mathrm{~m}, \mathrm{~L} \times \mathrm{W} \times \mathrm{H}$ : $)$ for 4 hours. A $150-\mathrm{W}$ infrared bulb on one side of the terrarium provided heat; illumination was provided by parabolic aluminized reflector (PAR) lights. While in the terrarium, lizards were fed crickets (Acheta 
Table 1. Liolaemus species used in this study

\begin{tabular}{|c|c|c|c|}
\hline \multirow[b]{2}{*}{ Species } & \multicolumn{2}{|c|}{ Number of individuals } & \multirow[b]{2}{*}{ Location } \\
\hline & Males & Females & \\
\hline L. baguali & 6 & 2 & Santa Cruz, $20 \mathrm{~km} \mathrm{NW}$ int. RN40 and RP29; $48^{\circ} 40^{\prime} 40.5^{\prime \prime} \mathrm{S}, 71^{\circ} 07^{\prime} 57.2^{\prime \prime} \mathrm{W}$ \\
\hline L. bibroni & 4 & 4 & Santa Cruz, Tres Cerros on RN3; $48^{\circ} 06^{\prime} 36.8^{\prime \prime} \mathrm{S}, 67^{\circ} 38^{\prime} 09.8^{\prime \prime} \mathrm{W}$ \\
\hline L. canqueli & 7 & 4 & Chubut, $45 \mathrm{~km}$ Pampa de Agnia; $43^{\circ} 50^{\prime} 43.2^{\prime \prime} \mathrm{S}, 69^{\circ} 09^{\prime} 53.5^{\prime \prime} \mathrm{W}$ \\
\hline L. ceii & 3 & 5 & Neuquén, $20 \mathrm{~km}$ E of Villa Pehuenia; $38^{\circ} 54^{\prime} 06.2^{\prime \prime S}, 70^{\circ} 52^{\prime} 13.1^{\prime \prime} \mathrm{W}$ \\
\hline L. coeruleus & 13 & 5 & Neuquén, $36 \mathrm{~km}$ E of Villa Pehuenia; $38^{\circ} 53^{\prime} 34.1^{\prime \prime} \mathrm{S}, 70^{\circ} 40^{\prime} 57.3^{\prime \prime} \mathrm{W}$ \\
\hline L. elongatus & 7 & 9 & Neuquén, $36 \mathrm{~km} \mathrm{E}$ of Villa Pehuenia; $38^{\circ} 53^{\prime} 34.1^{\prime \prime} \mathrm{S}, 70^{\circ} 40^{\prime} 57.3^{\prime \prime} \mathrm{W}$ \\
\hline L. escachardosi & 4 & 2 & Santa Cruz, $62 \mathrm{~km} \mathrm{E}$ from El Calafate on RN $40 ; 50^{\circ} 24^{\prime} 41.8^{\prime \prime} \mathrm{S}, 71^{\circ} 30^{\prime} 56.6^{\prime \prime}$ \\
\hline L. fitzingerii & 4 & 6 & Santa Cruz, RN40 E of Lake Cardiel; $48^{\circ} 56^{\prime} 34.6^{\prime \prime} \mathrm{S}, 71^{\circ} 02^{\prime} 03.7^{\prime \prime}$ \\
\hline L. hatcheri & 7 & 5 & Santa Cruz, $22 \mathrm{~km} \mathrm{NW}$ int. RN40 and RP29; $48^{\circ} 39^{\prime} 50.8^{\prime \prime} \mathrm{S}, 71^{\circ} 07^{\prime} 23,5^{\prime \prime} \mathrm{W}$ \\
\hline L. kingii & 3 & 7 & Santa Cruz, $1 \mathrm{~km} \mathrm{~N}$ Tres Cerros on RN3; $47^{\circ} 56^{\prime} 28.2^{\prime \prime} \mathrm{S}, 67^{\circ} 32^{\prime} 04.4^{\prime \prime} \mathrm{W}$ \\
\hline L. kolengh & 7 & 4 & Santa Cruz, $76 \mathrm{~km} \mathrm{~S}$ of Los Antiguos on RP41; $46^{\circ} 59^{\prime} 32.1^{\prime \prime} \mathrm{S}, 71^{\circ} 49^{\prime} 28.2^{\prime \prime} \mathrm{W}$ \\
\hline L. mapuche & 11 & 5 & Neuquén, $41 \mathrm{~km} \mathrm{~W}$ of Cutral-co; $38^{\circ} 55^{\prime} 39.2^{\prime \prime} \mathrm{S}, 69^{\circ} 41^{\prime} 13.2^{\prime \prime} \mathrm{W}$ \\
\hline L. morenoi & 6 & 7 & Neuquén, $30 \mathrm{~km} \mathrm{~S}$ of Zapala; $39^{\circ} 02^{\prime} 45.1^{\prime \prime} \mathrm{S}, 70^{\circ} 00^{\prime} 46.4^{\prime \prime} \mathrm{W}$ \\
\hline L. petrophilus & 2 & 7 & Chubut, $30 \mathrm{~km} \mathrm{E}$ of Gualjaina; $42^{\circ} 38^{\prime} 16.6^{\prime \prime} \mathrm{S}, 70^{\circ} 12^{\prime} 42.7^{\prime \prime} \mathrm{W}$ \\
\hline L. rothi & 3 & 3 & Rio Negro, $175 \mathrm{~km}$ S of Gral. Roca on RP6; $40^{\circ} 17^{\prime} 17,8^{\prime \prime S}, 68^{\circ} 27^{\prime} 26,9^{\prime \prime} \mathrm{W}$ \\
\hline L. sarmientoi & 4 & 2 & Santa Cruz, on RP5 $3 \mathrm{~km} \mathrm{~W}$ from crossroad with RN3; $51^{\circ} 36^{\prime} 58.6^{\prime \prime} \mathrm{S}, 69^{\circ} 40^{\prime} 02.6^{\prime \prime} \mathrm{W}$ \\
\hline L. tenuis & 4 & 3 & Neuquen, coast of Lake Aluminé near RP13; $38^{\circ} 53^{\prime} 50.0^{\prime \prime} \mathrm{S}, 71^{\circ} 07^{\prime} 27.9^{\prime \prime} \mathrm{W}$ \\
\hline L. xanthoviridis & 5 & 2 & Chubut, $20 \mathrm{~km} \mathrm{~S}$ of Trelew on RP1; $43^{\circ} 24^{\prime} 43.5^{\prime \prime} \mathrm{S}, 65^{\circ} 18^{\prime} 09.9^{\prime \prime} \mathrm{W}$ \\
\hline L. zullyi & 5 & 3 & Santa Cruz, $30 \mathrm{~km} \mathrm{~S}$ of Los Antiguos on RP41; $46^{\circ} 56^{\prime} 54.7^{\prime \prime} \mathrm{S}, 71^{\circ} 51^{\prime} 13.1^{\prime \prime} \mathrm{W}$ \\
\hline
\end{tabular}

Number of individuals (per sex) and location (province, location name, and latitude and longitude) of capture are given.

domestica) ad libitum and were sprayed with water at least twice. All morphological and bite-force measurements were performed within a maximum of 4 weeks of capture. Only individuals in good condition were used in bite-force trials.

\section{MORPHOLOGY}

We took the following morphological measurements on all individuals using digital callipers (Mitutoyo): snout-vent length (SVL), head length (HL), head width (HW), head height (HH), lower jaw length (LJL), the jaw outlever (JO), and the distance from the coronoid bone (estimated by the posterior edge of the jugal) to the tip of the lower jaw (CT). Head length was measured from the posterior edge of the parietal bone to the tip of the snout; head width was measured at the widest part of the head; head height was measured at the highest part of the head; lower jaw length was measured from the back of the retroarticular process to the tip of the lower jaw; the jaw outlever was measured as the distance between the jaw articulation to the tip of the lower jaw. In addition, we estimated two extra morphological variables reflecting the biomechanics of the jaw system by subtracting the jaw outlever from the lower jaw length (i.e. the inlever for jaw opening), and by subtracting $\mathrm{CT}$ from the jaw outlever (i.e. the inlever for jaw closing; see Fig. 1). Bony elements used to delineate morphological segments could be detected easily through palpation.

\section{BITE FORCE}

We measured the in vivo bite force for all individuals using an isometric Kistler force transducer (type 9203) mounted on a purpose-built holder and connected to a Kistler charge amplifier (type 5995; see Herrel et al., 1999 for a detailed description of the set-up). We induced the lizards to bite the force transducer by tapping them on the side of the mouth. The tapping typically resulted in a threat response in which the jaws are opened maximally. The free ends of the holder (bite plates) were then placed between the jaws, which resulted in prolonged biting. Each bite was scored as 'good' or 'bad' based on the willingness of the lizard to bite the plates, and the vigour with which it bit. We only used individuals for which we obtained at least five 'good' bites. As an estimate of maximal bite-force capacity, we used the highest bite force out of the five bites for each individual.

At least 1 hour before the start of the bite-force measurements, and in between trials, lizards were released in a terrarium with a heat lamp on one side so that lizards could reach their preferred body temperature. 


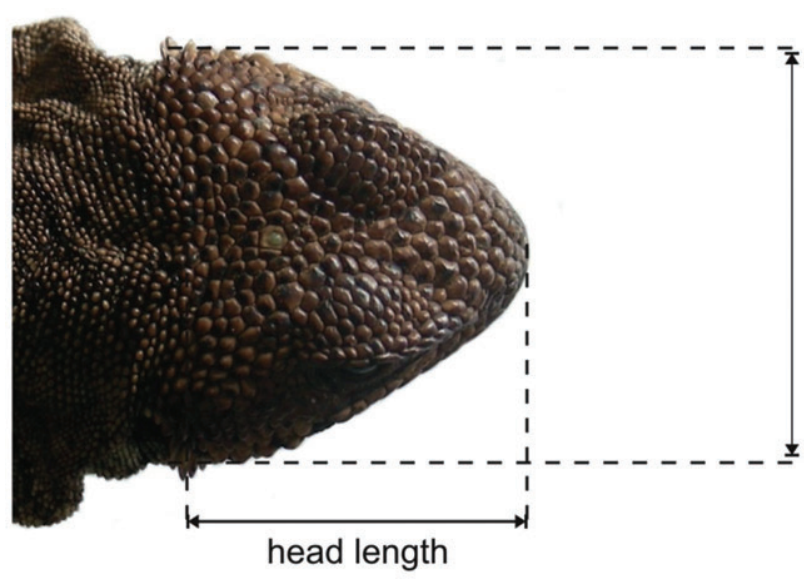

head width

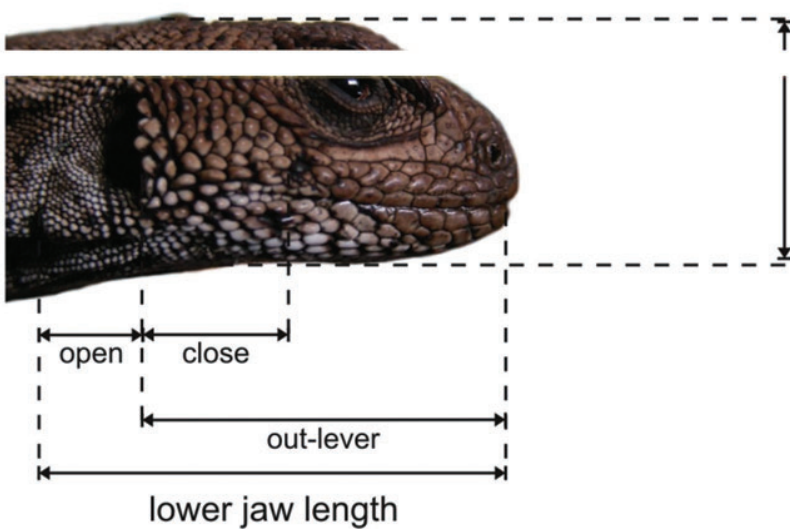

head height

Figure 1. Picture of a head of a Liolaemid lizard (Phymaturus tenebrosus), in dorsal (top) and lateral (bottom) view. Shown are the morphological measurements taken for each individual (see text for more details).

\section{DIET}

Upon arrival in the lab at INIBIOMA in Bariloche, Argentina, we collected the faeces from the cloth bag, in which the individuals of a single species and location were kept. Faeces from different bags were stored separately in paper bags for further identification. We note that faeces could not be assigned to a particular individual or sex by this method. Although species were kept apart, data for males and females were pooled, and consequently we could not explore potential dietary divergence between the sexes. Before identifying the faeces contents, the faeces were rehydrated for $30 \mathrm{~min}$. They were analysed under a microscope (Olympus) and flower buds, seeds, fruits, and insects were separated. Insects were identified to the lowest taxonomical order possible. The different prey types were separated into plant versus animal matter, and were classified according to taxonomical order and functional properties (i.e. hardness and evasiveness). The latter is based on the classification used in Vanhooydonck, Herrel \& Van Damme (2007), and results in three hardness groups (i.e. hard, soft, and intermediate) and two evasiveness groups (i.e. evasive versus sedentary).

The contribution of each prey type to the diet of a species was estimated in terms of volume. However, most items could only be partly recovered from the faeces because they were bitten into pieces by the lizard or were partly digested. We were therefore unable to obtain reliable volume estimates for each item, and decided to estimate the volumes in relative terms. We did so in the following way. We used the volume of the smallest prey item found in any of the faecal pellets as the 'unit volume', and expressed the volume of all other prey items in this unit. The estimation of volumes was based on the (presumed) volume of prey items as a whole, i.e. prior to crushing and/or ingestion. To calculate the contribution of the different prey types (i.e. vegetal versus animal matter; hard, soft, and intermediately hard prey; and sedentary versus evasive prey) to the total prey volume, we first summed the volumes of all the prey 
items belonging to the same prey type. Subsequently, we estimated the proportion of plant material, the proportion of hard prey, soft prey, intermediate prey, and evasive prey, expressed in relative volume, per species as the ratio of the volume of the prey type of interest against the total volume. We did not calculate the proportions of animal material or the proportion of sedentary prey in the diet, as these are by definition complementary to the proportion of plant material and the proportion of sedentary prey, respectively.

\section{ANALYSES}

Raw data (species means and standard errors) of all morphological variables, bite force, and diet are listed in Appendices 1 and 2.

We calculated the mean values of the morphological and performance variables per species and sex, and logarithmically $\left(\log _{10}\right)$ transformed them prior to analyses. As for the diet variables, proportions were estimated per species and then arcsine transformed. As an estimate of sexual selection, we calculated the sexual dimorphism in HW by taking the ratio of HW in males to HW in females (see Butler, Schoener \& Losos, 2000; Losos, Butler \& Schoener, 2003). We subsequently logarithmically $\left(\log _{10}\right)$ transformed the ratio. All analyses were run separately for males and females.

As species share part of their evolutionary history they cannot be regarded as independent data points in statistical analyses (Felsenstein, 1985, 1988; Harvey \& Pagel, 1991). To take this statistical nonindependence into account, we calculated independent contrasts (Felsenstein, 1985, 1988) of all the variables under study using the PDTREE program (Garland, Midford \& Ives, 1999). We subsequently regressed the independent contrasts of each morphological variable, sexual dimorphism, and bite force against the independent contrast of SVL (forced through the origin; see Garland et al., 1999), and calculated the residuals.

Calculating independent contrasts requires information on the topology and branch lengths of the phylogenetic tree. The phylogenetic tree of the 19 Liolaemus species studied here (Fig. 2) is based on a combination of morphological and mitochondrial DNA analyses of a much larger number of Liolaemus lizard species (Lobo, 2001, 2005; Espinoza et al., 2004; Abdala, 2007), and represents the 'best' current tree. We set the branch lengths to unity, as divergence times among the different species are unclear.

We tested for phylogenetic signal in all variables using a simple randomization test implemented in the PHYSIG program (Blomberg, Garland \& Ives, 2003). Using the same program, we calculated the K statistic to gauge the level of phylogenetic signal relative to the level expected for a character undergoing Brownian motion evolution along the specified topology and branch lengths (Blomberg et al., 2003). The SVL and all dietary variables (i.e. proportion of plant material in diet, and proportion of hard prey, soft prey, intermediate prey, and evasive prey) were introduced into PHYSIG after $\log _{10}$ and arcsine transformations, respectively. All other morphological variables (i.e. HL, HW, HH, JO, inlever for jaw closing, inlever for jaw opening, and CT) and sexual dimorphism in HW were size-corrected following the method suggested by Blomberg et al. (2003) prior to the calculation of the level of phylogenetic signal present in these traits.

We ran seven multiple regression analyses on the independent contrasts with different sets of dependent and independent variables for males and females separately to test: (1) which morphological variables explain the variation in bite force; (2) whether variation in diet (i.e. proportions of plant material, and hard prey, soft prey, intermediate prey, and evasive prey) can be explained by the variation in morphology; and (3) whether the variation in relative bite force can be explained by the variation in sexual dimorphism and/or the variation in diet (i.e. sexualselection versus natural-selection hypotheses). To ascertain that our estimate of sexual selection, i.e. sexual dimorphism in HW, and its relation to the relative bite force does not confound the relationship between relative bite force and head morphology per se, we regressed (residual) sexual dimorphism in HW against the (residual) HW for each sex (regression through the origin). The relationship was nonsignificant in both males $(r=0.12, P=0.64)$ and females $(r=0.34, P=0.15)$.

The different sets of variables used in the different analyses are shown in Table 2. The selection of independent variables is based on biomechanical predictions and previously published empirical data with regard to the specific dependent variable. In all analyses, we used the backward selection method, and all regressions were forced through the origin (cf. Garland et al., 1999).

Finally, to ascertain that the variation in sexual dimorphism in head size is not related to our measure of the intensity of natural selection (i.e. variation in diet), we regressed the independent contrasts of each dietary variable (i.e. proportions of hard prey, soft prey, intermediate prey, evasive prey, and plant material) against the residual independent contrasts of sexual dimorphism in head width.

To enhance the readability of the text, we will refrain from stating specifically that we have used the independent contrast in each variable. Instead, we will use SVL, residual $\mathrm{HL}$, residual $\mathrm{HW}$, residual $\mathrm{HH}$, residual CT, residual jaw outlever, residual inlever for jaw opening, residual inlever for jaw closing, residual 


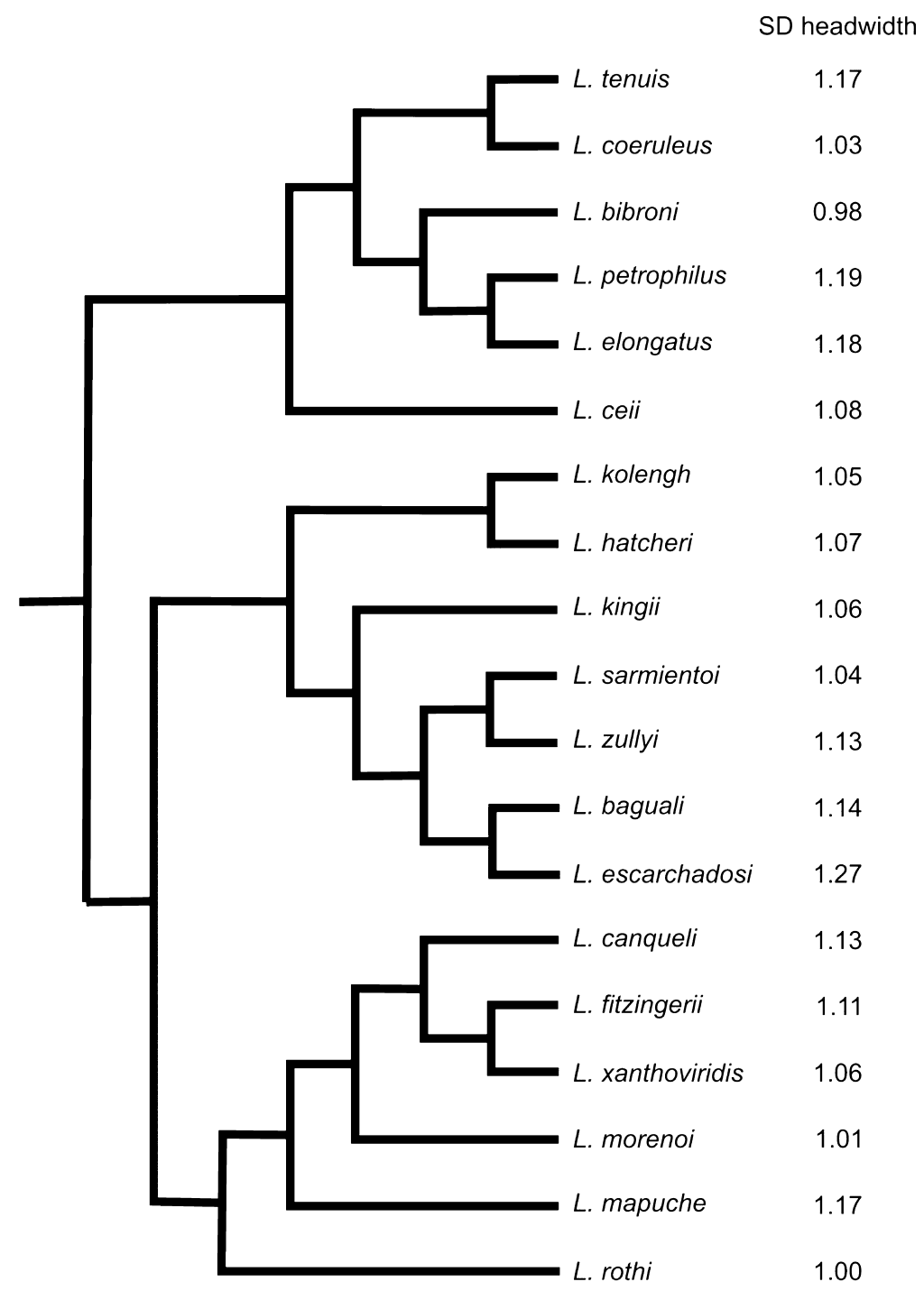

Figure 2. Phylogenetic relationships among the 19 Liolaemus species studied here. This currently 'best' tree is a combined tree based on morphological and molecular analyses reported in the literature (Lobo, 2001, 2005; Espinoza et al., 2004; Abdala, 2007). As divergence times are unknown, all branch lengths are set to unity.

bite force, and the proportions of plant material, and hard prey, soft prey, intermediate prey, and evasive prey throughout the remainder of the text.

\section{RESULTS}

\section{PHYLOGENETIC SIGNAL}

$K$ values, significance levels, and the observed $\mathrm{MSE}_{0} /$ MSE are given in Table 3 . The $K$ values for all variables, in both males and females, were lower than 1 . $K$ values lower than unity may be caused by deviation from Brownian motion and/or measurement error. The randomization tests showed that in males the level of phylogenetic signal present is significant in SVL and (relative) $\mathrm{HH}$, and is marginally non- significant in (relative) HW and bite force. The results are similar in females (Table 3): the level of phylogenetic signal present is significant in SVL, (relative) $\mathrm{HH}$ and $\mathrm{CT}$, and is marginally non-significant in (relative) HW. As for the dietary variables, the level of phylogenetic signal present is significant for the proportion of plant material, proportion of soft prey and evasive prey, and tends to significance for the proportion of intermediate prey (Table 3). This means that for these traits, the phylogenetic tree used fits the data better than a random tree.

\section{DIET}

We found three types of plant matter (i.e. flowers, fruits, and seeds) and six different types of arthropods 
Table 2. All multiple regressions, with dependent and independent variables given, performed on the independent contrasts for males and females separately

\begin{tabular}{|c|c|}
\hline Dependent & Independent \\
\hline Residual bite force & $\begin{array}{l}\text { Residual head length } \\
\text { Residual head width } \\
\text { Residual head height } \\
\text { Residual inlever jaw closing } \\
\text { Residual CT }\end{array}$ \\
\hline Proportion plant material & $\begin{array}{l}\text { Snout-vent length } \\
\text { Residual head length } \\
\text { Residual head width } \\
\text { Residual head height } \\
\text { Residual inlever jaw closing } \\
\text { Residual CT }\end{array}$ \\
\hline Proportion hard prey & $\begin{array}{l}\text { Snout-vent length } \\
\text { Residual head length } \\
\text { Residual head width } \\
\text { Residual head height } \\
\text { Residual inlever jaw closing } \\
\text { Residual CT }\end{array}$ \\
\hline Proportion soft prey & $\begin{array}{l}\text { Snout-vent length } \\
\text { Residual head length } \\
\text { Residual head width } \\
\text { Residual head height } \\
\text { Residual inlever jaw closing } \\
\text { Residual CT }\end{array}$ \\
\hline Proportion intermediate prey & $\begin{array}{l}\text { Snout-vent length } \\
\text { Residual head length } \\
\text { Residual head width } \\
\text { Residual head height } \\
\text { Residual inlever jaw closing } \\
\text { Residual CT }\end{array}$ \\
\hline Proportion evasive prey & $\begin{array}{l}\text { Snout-vent length } \\
\text { Residual head length } \\
\text { Residual head width } \\
\text { Residual head height } \\
\text { Residual outlever jaw opening } \\
\text { Residual inlever jaw opening }\end{array}$ \\
\hline Residual bite force & $\begin{array}{l}\text { Residual SD head width } \\
\text { Proportion plant material } \\
\text { Proportion hard prey } \\
\text { Proportion soft prey } \\
\text { Proportion intermediate prey } \\
\text { Proportion evasive prey }\end{array}$ \\
\hline
\end{tabular}

[i.e. ants (Formicidae), spiders (Araneae), larvae, cockroaches (Blattaria), beetles (Coleoptera), and grashoppers (Orthoptera)] in the faecal pellets of the 19 Liolaemus species under study here. Fruits, ants, spiders, larvae, and cockraoches were classified as soft prey; grasshoppers and flowers were classified as being intermediate in hardness; coleopterans and seeds were classified as hard prey; and ants, cockroaches, coleopterans, and grasshoppers were
Table 3. $K$ statistic, observed $\mathrm{MSE}_{0} / \mathrm{MSE}$ and $P$ value for all variables used in the analyses

\begin{tabular}{|c|c|c|c|}
\hline Variable & $K$ & $\begin{array}{l}\text { Observed } \\
\mathrm{MSE}_{0} / \mathrm{MSE}\end{array}$ & $P$ \\
\hline \multicolumn{4}{|l|}{ MALES } \\
\hline SVL & 0.630 & 1.103 & 0.018 \\
\hline SD headwidth & 0.474 & 0.829 & 0.202 \\
\hline Head length & 0.382 & 0.668 & 0.514 \\
\hline Head width & 0.877 & 1.534 & 0.077 \\
\hline Head height & 0.635 & 1.111 & 0.020 \\
\hline Outlever & 0.389 & 0.681 & 0.459 \\
\hline $\mathrm{CT}$ & 0.441 & 0.772 & 0.247 \\
\hline Open inlever & 0.466 & 0.815 & 0.200 \\
\hline Close inlever & 0.526 & 0.920 & 0.181 \\
\hline Bite force & 0.648 & 1.133 & 0.067 \\
\hline \multicolumn{4}{|l|}{ FEMALES } \\
\hline SVL & 0.635 & 1.110 & 0.022 \\
\hline SD headwidth & 0.449 & 0.786 & 0.439 \\
\hline Head length & 0.413 & 0.723 & 0.444 \\
\hline Head width & 0.585 & 1.024 & 0.069 \\
\hline Head height & 0.827 & 1.447 & 0.003 \\
\hline Outlever & 0.481 & 0.842 & 0.215 \\
\hline CT & 0.727 & 1.273 & 0.013 \\
\hline Open inlever & 0.389 & 0.645 & 0.811 \\
\hline Close inlever & 0.367 & 0.643 & 0.601 \\
\hline Bite force & 0.621 & 1.087 & 0.113 \\
\hline Proportion volume plant & 0.737 & 1.290 & 0.019 \\
\hline Proportion volume hard & 0.547 & 0.957 & 0.120 \\
\hline Proportion volume soft & 0.853 & 1.493 & 0.007 \\
\hline Proportion volume intermediate & 0.716 & 1.253 & 0.073 \\
\hline Proportion volume evasive & 0.759 & 1.329 & 0.008 \\
\hline
\end{tabular}

All morphological variables, except snout-vent length (SVL) and bite force, are size-corrected following the method suggested by Blomberg et al. (2003). Phylogenetic signals are calculated for males and females seperately, except for dietary variables. Variables showing significant phylogenetic signals $(P<0.05)$ are set in bold; variables that show a tendency towards significance are set in italic $(P<0.10)$.

classified as evasive prey (cf. Vanhooydonck et al., 2007).

As for the estimation of the volumes of the different prey types, ants, being the smallest prey, were used as the unit of volume. In doing so, we considered (the volume of) one seed to be equal to (the volume of) two ants, one coleopteran to be equal to three ants, one grasshopper, cockroach, spider, larva, or fruit to be equal to five ants, and one flower to be equal to six ants. This provides us with a relative index of the volume contribution of each prey type in the diet.

\section{HEAD MORPHOLOGY AND BITE FORCE}

In males, the multiple regression analysis with residual bite force as the dependent variable, and with 
Table 4. Results of the multiple regressions on the independent contrasts in females

\begin{tabular}{|c|c|c|c|c|c|}
\hline Dependent & $r$ & $F_{\mathrm{df1} 1 \mathrm{df} 2}$ & $P$ & Independent & Partial $r$ \\
\hline Residual bite force & 0.75 & $4.53_{4,14}$ & 0.015 & $\begin{array}{l}\text { Residual head length } \\
\text { Residual head width } \\
\text { Residual inlever jaw closing } \\
\text { Residual CT }\end{array}$ & $\begin{array}{r}-0.49 \\
-0.61 \\
0.69 \\
0.46\end{array}$ \\
\hline Proportion plant material & 0.69 & $4.44_{3,15}$ & 0.020 & $\begin{array}{l}\text { Snout-vent length } \\
\text { Residual head length } \\
\text { Residual CT }\end{array}$ & $\begin{array}{r}0.53 \\
0.45 \\
-0.55\end{array}$ \\
\hline Proportion soft prey & 0.55 & $3.38_{2,16}$ & 0.060 & $\begin{array}{l}\text { Residual head length } \\
\text { Residual CT }\end{array}$ & $\begin{array}{r}-0.50 \\
0.54\end{array}$ \\
\hline Proportion evasive prey & 0.44 & $4.12_{1,17}$ & 0.058 & Snout-vent length & -0.44 \\
\hline
\end{tabular}

Only results on significant models are shown, and significant independent variables and their partial correlations (partial $r$ ) are given.

residual $\mathrm{HL}, \mathrm{HW}, \mathrm{HH}, \mathrm{CT}$, and inlever for jaw closing as independent variables, results in a significant model, in which residual $\mathrm{HL}$ and $\mathrm{CT}$ are retained $\left(r=0.71, F_{2,16}=8.26, P=0.003\right)$. Whereas residual $\mathrm{HL}$ is positively correlated with residual bite force (partial $r=0.69$ ), the variation in $\mathrm{CT}$ is negatively correlated (partial $r=-0.56$ ), indicating that males with long heads but short snouts bite relatively harder.

In females, the analogous multiple regression analysis also results in a significant model, but four independent variables are retained (i.e. residual HL, HW, CT, and inlever of jaw closing; Table 4). Whereas the variation in residual HL and HW are negatively (partially) correlated with the variation in residual bite force, the variation in residual CT and the inlever for jaw closing are positively (partially) correlated. Thus, females with short and narrow heads, but long snouts and greater jaw-closing inlevers, are better biters.

\section{MORPHOLOGY AND DIET}

In males, none of the multiple regressions with a dietary variable as the dependent variable, and all morphological variables entered as independent variables, resulted in a significant model. In the regressions, the $F$ and $P$ values of the 'best' model (i.e. highest $F$ value and lowest $P$ value) are smaller than 2.70 and greater than 0.10 , respectively.

In females, the multiple regression analysis with plant material as the dependent variable resulted in a significant model in which SVL, residual HL and CT are retained (Table 4 ). The variation in both SVL and HL are positively (partially) correlated with the variation in proportion of plant material in the diet, whereas the variation in CT is negatively (partially) correlated (Table 4).

Both multiple regressions with the proportion of soft prey in the diet and the proportion of evasive prey yield marginally non-significant models (Table 4). In the former, the variation in residual HL is negatively (partially) correlated with the variation in the proportion of soft prey, and the variation in residual CT is positively correlated (Table 4). In the latter, only the variation in SVL is retained, and it tends to be negatively correlated with the variation in the proportion of evasive prey (Table 4).

The multiple regressions with the proportion of hard prey and the proportion of intermediate prey did not result in a significant model (both 'best' models: $F<1.88 ; P>0.176)$.

\section{SEXUAL DIMORPHISM, DIET, AND BITE FORCE}

The multiple regression analysis with residual bite force as the dependent variable, and with the proportions of plant material, hard prey, soft prey, intermediate prey, and evasive prey in the diet, and the residual sexual dimorphism in $\mathrm{HW}$ as independent variables, resulted in a significant model in which only the latter variable was retained $\left(r=0.48, F_{1}\right.$, $17=5.03, P=0.039$; Fig. 3A) for males. In females, the multiple regression analysis resulted in a marginally non-significant model in which the proportion of soft prey in the diet was retained $\left(r=0.45 ; F_{1,17}=4.19\right.$, $P=0.056$; Fig. 3B). These results suggest that in males, the evolution of residual bite force correlates positively with the evolution of sexual dimorphism among the 19 Liolaemus species under study, whereas in females it tends to correlate with some aspects of the diet.

In addition, none of the regressions of the variation in any dietary variable against sexual dimorphism in head size were significant (all $r<0.21, P>0.39$ ), suggesting variation in diet does not explain the observed variation in sexual head size dimorphism in these lizards. 

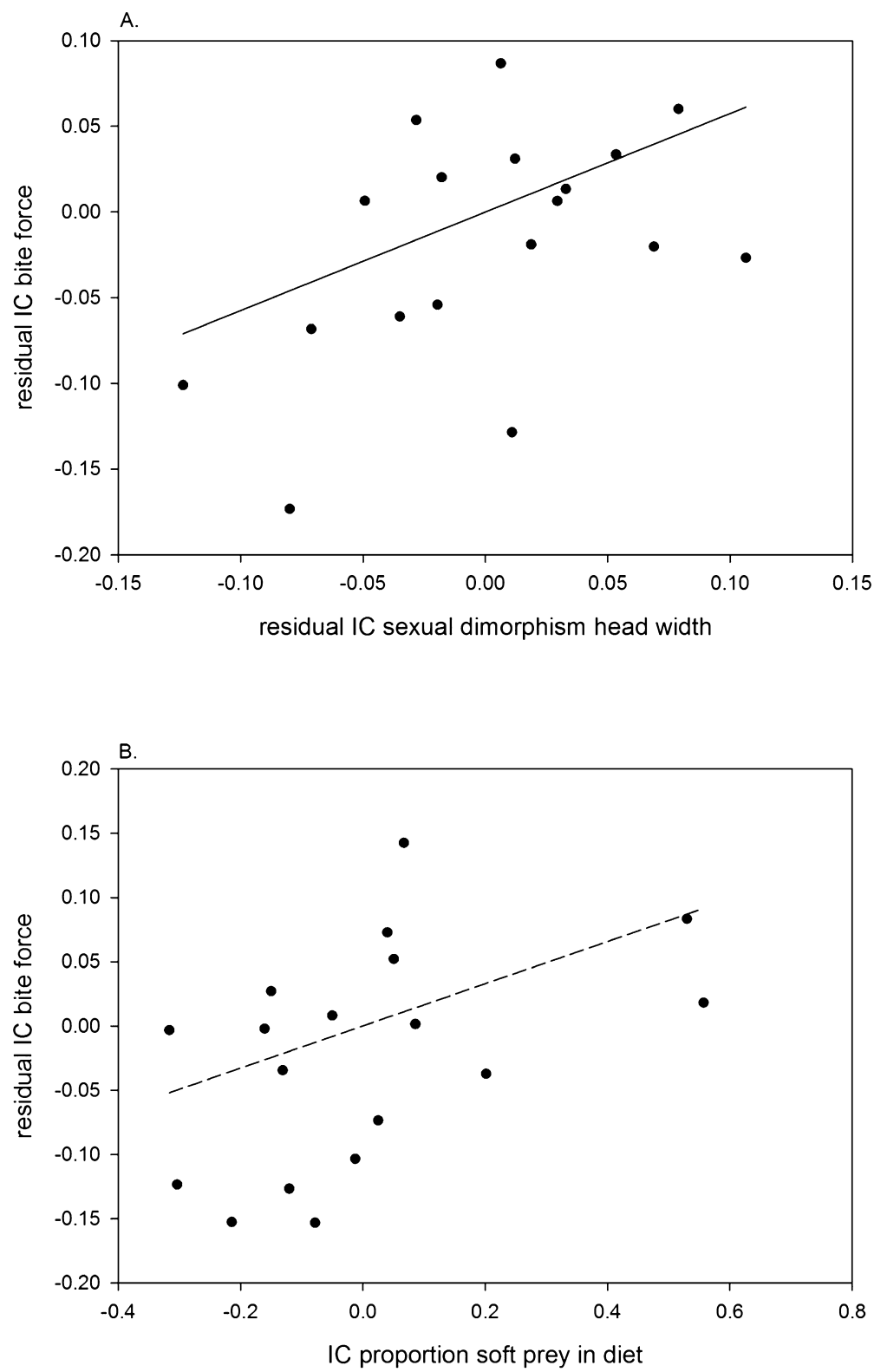

Figure 3. Plot of the residual independent contrasts of (A) bite force against the residual independent contrasts of sexual dimorphism in head width in males $(r=0.48, P=0.039)$, and (B) bite force in females against the independent contrasts of proportion of soft prey in the $\operatorname{diet}(r=0.45, P=0.056)$. The marginally non-significant relationship in (B) is represented by a dashed line. Relative bite force may thus be, at least partly, under sexual selection in males, whereas in females the variation in relative bite force seems related to the variation in diet.

\section{DISCUSSION}

Our results show that among Liolaemus species, none of the variation in dietary variables explains a significant proportion of the variation in sexual head size dimorphism, suggesting natural selection related to the ability of the different species to eat different prey is not responsible for the sexual differences in head size. More importantly, the variation in male (relative) bite force is explained, at least partly, by the variation in sexual dimorphism in $\mathrm{HW}$, and none of the morphological variables seem to correlate with dietary variables. On the contrary, in females the variation in bite force and head size seems linked, at least partly, to the variation in diet. Also, the level of phylogenetic signal (i.e. $K$ statistic) in all variables 
(morphology, performance, and diet) appears to be lower than one, i.e. they all show less signal than expected given the topology, branch lengths, and a Brownian motion model of evolution. This may be attributed to adaptation and/or measurement error, such as errors in the estimates of morphology, bite performance, and diet, and branch lengths and topology used in the analyses (Blomberg et al., 2003). As for some of these variables randomization tests showed the presence of a phylogenetic signal, it provides justification for the claim that species cannot be regarded as independent data points in statistical analyses (Blomberg et al., 2003). We note, however, that using 19 species is close to the sample size limit (i.e. 20 species) for obtaining reliable estimates in this kind of analysis (see Blomberg et al., 2003).

\section{BITE FORCE AND MORPHOLOGY}

As for the relationship between (relative) bite force and head size, our results show that in males the variation in bite force is determined by the variation in relative $\mathrm{HL}$ and snout length (i.e. the distance from the back of the jugal to the tip of the snout). More specifically, males that are able to bite hard for their body size have relatively long heads but short snouts. From a biomechanical perspective these results are logical. In general, larger heads, more robust skulls, larger muscles, or a combination of all generate higher forces (see Herrel, Van Damme \& De Vree, 1996; Herrel et al., 1999, 2001a, b; Herrel, McBrayer \& Larson, 2007). In addition, longer heads result in a larger gape, thus enabling the animal to eat large prey (Herrel et al., 1996, 1999). The negative relationship between relative bite force and snout length is also intuitively obvious, as shorter snouts decrease the jaw outlever while maximizing the inlever for jaw closing, and thus optimizing bite force at the tip of the jaws.

In females, however, the results are quite different. Unexpectedly, females that are able to bite hard for their body size have relatively short and narrow heads, but long snouts and greater inlevers for jaw closing. Although the latter can be explained by the fact that it offers more space for muscles involved in jaw closing, and thus results in greater bite forces (Herrel et al., 1996, 1999, 2007), the relationship between bite force and the other three variables is opposite to the one expected based on biomechanical predictions, and differs from what was observed for males. Although some of the variation in head size seems correlated with dietary variation directly (see below), the bite force-morphology relationship in females remains unexplained. Still, as bite force is influenced by other morphological and physiological traits, such as the size, orientation, and physiological properties of the jaw muscles, and skull dimensions (Herrel et al., 1996, 1999, 2001b, 2007; Huyghe et al., 2009), only testing for correlations between external head measurements and bite force may be overly simplistic. Alternatively, the increase in jaw closing inlever may suffice to generate higher bite forces while at the same time allowing females to have short and narrow heads. This would suggest, however, that alternative selective pressures are operating on head size in females.

\section{BITE FORCE AND HEAD SIZE: NATURAL VERSUS SEXUAL SELECTION}

The differential relationships between bite performance, diet, morphology, and sexual dimorphism in the two sexes suggest that male and female Liolaemus lizards are subjected to different selective pressures. As the variation in relative bite force in males seems to be explained by (our measure of) the intensity of sexual selection (i.e. sexual dimorphism in HW), and not by the variation in diet (i.e. natural selection), it suggests bite force, and associated head size, is sexually selected for. Although behavioural observations on Liolaemus lizards and knowledge of the social system are scarce, it has been shown in other lizards that in male-male encounters, the male with the greatest bite force and/or largest head typically wins the fight (Anderson \& Vitt, 1990; MolinaBorja et al., 1998; Herrel et al., 1999; Kratochvíl \& Frynta, 2002; Lailvaux et al., 2004; Huyghe et al., 2005 ) and acquires high-quality territories (Lappin \& Husak, 2005). In addition, it has been suggested that bite force and head size may be important for males in an intersexual context, as they need to grab and hold on to females to be able to copulate (i.e. mating bites; Herrel et al., 1996; Gvoždík \& Van Damme, 2003).

In females, we do find some evidence for natural selection acting on bite force and head size, as they are correlated to some degree with the variation in diet. First, in females, the proportion of evasive (insect) prey in the diet is correlated with body size, i.e. smaller animals seem to eat more evasive prey. This is not surprising as small body size may enhance maneuverability and acceleration capacity (e.g. Hill, 1950; Hedenström \& Møller, 1992; Wilson, Franklin \& James, 2000; Vanhooydonck et al., 2006 but see Huey $\&$ Hertz, 1984), thus enabling the predator to chase and capture highly active prey. Conversely, larger body size is often associated with the inclusion of plant matter in the diet in many lizards in general (Van Damme, 1999; Cooper \& Vitt, 2002; Herrel et al., 2004a), and in liolaemids. More specifically, in female liolaemids, more plant material is included in the diet by species with a larger body size, and with relatively 
long heads and short snouts. These results are in line with biomechanical predictions and empirical data on body size and head size in other omnivorous lizards (Herrel et al., 1999, 2004a; Herrel, Vanhooydonck \& Van Damme, 2004b).

Lastly, the variation in relative bite force is positively correlated with the variation in the proportion of soft prey in the diet, i.e. female Liolaemus lizards feeding on mostly soft prey are the hardest biters. Although the morphological variation associated with the number of soft prey seems in line with the biomechanical predictions (i.e. short heads and long CT distances or snouts), the same variables seem (partially) correlated with bite force. The fact that the same morphological variables underlie both the number of soft prey consumed and bite force may thus explain the unexpected, and potentially indirect, positive correlation between the two variables. Also, we note that most liolaemids feed primarily on ants. In this case, contrary to earlier classifications (cf. Vanhooydonck et al., 2007), we classified ants as soft prey as they are not crushed before being swallowed (see Appendix 2). Although no clear predictions on the relationship with head morphology and bite force have been put forward for ant specialists, it has been shown previously that prey capture in species with an ant-based diet is associated with unusual feeding behaviours, such as extremely rapid tongue protrusion and a reduced degree of prey processing (Meyers $\&$ Herrel, 2005). How such a specialized diet translates specifically into differences in head morphology and changes in bite capacity needs further investigation. Still, we believe that the opposite correlations between bite force and diet on the one hand and some of the same head size variables on the other, best explains the absence of the link between bite force and the consumption of vegetal and/or hard matter. Data on the seasonal variation in diet and the use of other techniques to estimate dietary variation would be valuable additions here that could explain this apparent paradox.

We note that our findings need to be interpreted with caution as diet data were pooled for both sexes per species. We realize this might obscure sex-specific relationships between the variation in head morphology, bite performance, and diet. Still, we believe our results suggest sexual selection plays a role in the evolution of bite performance in male Liolaemus lizards, as sexual dimorphism in HW explained a significant proportion of the variation in bite performance. In addition, bite strength in males in 18 of the 19 species under study (see Appendix 1) largely exceeds the level of force generally needed to crush the prey items, such as arthropods, fruits, and seeds, found in the faeces (i.e. around $3 \mathrm{~N}$, except for some beetles; Herrel et al., 1996; Andrews \& Bertram,
1997; Herrel et al., 1999, 2001b; Aguirre et al., 2003). The same holds for females in 16 out of the 19 species. The comparison between in vivo bite strength and force needed to crush prey items is at least suggestive of other selection pressures, besides natural selection, acting on bite performance in Liolaemids.

\section{ACKNOWLEDGEMENTS}

All experiments were performed with the approval of the Agencia Nacional de Promoción Cientifica y Tecnologica (ANIPICyT). This work was supported by a scientific grant (PICT 01205) to FBC and a grant from the ATM program 'Formes possibles, formes realisees' of the Musée National d'Histoire Naturelle (Paris, France) to A.H. B.V. is a post-doctoral fellow of the Flemish Science Foundation (FWO-Vl).

\section{REFERENCES}

Abdala CS. 2007. Phylogeny of the boulengeri group (Iguania : Liolaemidae, Liolaemus) based on morphological and molecular characters. Zootaxa 1538: 1-84.

Aguirre LF, Herrel A, Van Damme R, Mathyssen E. 2003. The implications for food hardness for diet in bats. Functional Ecology 17: 201-212.

Anderson RA, Vitt LJ. 1990. Sexual selection versus alternative causes of sexual dimorphism in teiid lizards. Oecologia 84: 145-157.

Andrews C, Bertram JEA. 1997. Mechanical work as a determinant of prey-handling behavior in the Tokay gecko (Gekko gecko). Pysiological Zoology 70: 193-201.

Arnold SJ. 1983. Morphology, performance and fitness. American Zoologist 23: 347-361.

Blomberg SP, Garland T Jr, Ives AR. 2003. Testing for phylogenetic signal in comparative data: behavioral traits are more labile. Evolution 57: 717-745.

Brecko J, Huyghe K, Vanhooydonck B, Herrel A, Grbac I, Van Damme R. 2008. Functional and ecological relevance of intraspecific variation in body size and shape in a lizard, Podarcis melisellensis. Biological Journal of the Linnean Society 94: 251-264.

Butler MA. 2007. Vive le difference! Sexual dimorphism and adaptive patterns in lizards of the genus Anolis. Integrative and Comparative Biology 47: 272-284.

Butler MA, Schoener TW, Losos JB. 2000. The relationship between sexual size dimorphism and habitat use in Greater Antillean Anolis lizards. Evolution 54: 259-272.

Cooper WE, Vitt LJ. 2002. Distribution, extent, and evolution of plant consumption by lizards. Journal of Zoology 257: 487-517.

Espinoza RE, Wiens JJ, Tracy CR. 2004. Recurrent evolution of herbivory in small, cold-climate lizards: breaking the ecophysiological rules of reptilian herbivory. Proceedings of the National Academy of Sciences 101: 16819-16824.

Felsenstein J. 1985. Phylogenies and the comparative method. American Naturalist 125: 1-15. 
Felsenstein J. 1988. Phylogenies and quantitative characters. Annual Review of Ecology and Systematics 19: 445471.

Fox SF, Shipman PA. 2003. Social behavior at high and low elevations: environmental release and phylogenetic effects in Liolaemus. In: Fox SF, McCoy JK, Baird TA, eds. Lizard social behavior. Baltimore: Johns Hopkins University Press, 310-355.

Frutos N, Camporro LA, Avila LJ. 2007. Ambito de hogar de Liolaemus melanops burmeister, 1888 (Squamata: Liolaemini) en el centro de Chubut, Argentina. Gayana 71: 142-149.

Garland T Jr, Midford PE, Ives AR. 1999. An introduction to phylogenetically based statistical methods, with a new method for confidence intervals on ancestral states. American Zoologist 39: 374-388.

Gvoždík L, Van Damme R. 2003. Evolutionary maintenance of sexual dimorphism in head size in the lizard Zootoca vivipara: a test of two hypotheses. Journal of Zoology London 259: 7-13.

Halloy M, Robles C. 2002. Spatial distribution in a neotropical lizard, Liolaemus quilmes (Liolaemidae): site fidelity and overlapping among males and females. Bulletin of the Maryland Herpetological Society 38: 118-129.

Harvey PH, Pagel MD. 1991. The comparative method in evolutionary biology. Oxford: Oxford University Press.

Hedenström A, Møller AP. 1992. Morphological adaptations to song flight in passerine birds: a comparative study. Proceedings of the Royal Society of London B 247: 183187.

Herrel A, Van Damme R, De Vree F. 1996. Sexual dimorphism of head size in Podarcis hispanica atrata: testing the dietary divergence hypothesis by bite force analysis. Netherlands Journal of Zoology 46: 253-262.

Herrel A, Spithoven L, Van Damme R, De Vree F. 1999. Sexual dimorphism of head size in Gallotia galloti: testing the niche divergence hypothesis by functional analyses. Functional Ecology 13: 289-297.

Herrel A, Van Damme R, Vanhooydonck B, De Vree F. 2001a. The implications of bite performance for diet in two species of lacertid lizards. Canadian Journal of Zoology 79: 662-670.

Herrel A, De Grauw E, Lemos-Espinal JA. 2001b. Head shape and bite performance in Xenosaurid lizards. The Journal of Experimental Zoology 290: 101-107.

Herrel A, Vanhooydonck B, Joachim R, Irschick DJ. 2004a. Frugivory in polychrotid lizards: effects of body size. Oecologia 140: 160-168.

Herrel A, Vanhooydonck B, Van Damme R. 2004b. Omnivory in lacertid lizards: adaptive evolution or constraint? Journal of Evolutionary Biology 17: 974-984.

Herrel A, Joachim R, Vanhooydonck B, Irschick DJ. 2006. Ecological consequences of ontogenetic changes in head shape and bite performance in the Jamaican lizard Anolis lineatopus. Biological Journal of the Linnean Society 89: $443-454$.

Herrel A, McBrayer LD, Larson PM. 2007. Functional basis for sexual differences in bite force in the lizard Anolis lineatopus. Biological Journal of the Linnean Society 91: 111-119.

Herrel A, Huyghe K, Vanhooydonck B, Backeljau T, Breugelmans K, Grbac I, Van Damme R, Irschick DJ. 2008. Rapid large scale evolutionary divergence in morphology and performance associated with exploitation of a different dietary resource. Proceedings of the National Academy of Sciences 105: 4792-4795.

Hews DK. 1990. Examining hypotheses generated by field measures of sexual selection on male lizards, Uta palmeri. Evolution 44: 1956-1966.

Hill AV. 1950. The dimensions of animals and their muscular dynamics. Science Progress 38: 209-230.

Huey RB, Hertz PE. 1984. Effects of body size and slope on acceleration of a lizard (Stellio (Agama) stellio). Journal of Experimental Biology 110: 113-123.

Huey RB, Stevenson RD. 1979. Integrating thermal physiology and ecology of ectotherms: a discussion of approaches. American Zoologist 19: 357-366.

Husak JF, Lappin AK, Van Den Bussche RA. 2009. The fitness advantage of a high performance weapon. Biological Journal of the Linnean Society 96: 840-845.

Huyghe K, Vanhooydonck B, Scheers H, Molina-Borja M, Van Damme R. 2005. Morphology, performance and fighting capacity in male lizards, Gallotia galloti. Functional Ecology 19: 800-807.

Huyghe K, Herrel A, Adriaens D, Tadic Z, Van Damme R. 2009. It is all in the head. Morphological basis for differences in bite force among colour morphs of the Dalmatian wall lizard. Biological Journal of the Linnean Society 96: 13-22.

Irschick DJ, Meyers JJ, Husak JF, LeGalliard JF. 2008. How does selection operate on whole-organism performance capacities. Evolutionary Ecology Research 10: 177-196.

Jaksić FM, Núñez H, Ojeda FP. 1980. Body proportions, microhabitat selection, and adaptive radiation of Liolaemus lizards in central Chile. Oecologia 45: 178-181.

Kratochvíl L, Frynta D. 2002. Body size, male combat and the evolution of sexual dimorphism in eublepharid geckos (Squamata: Eublepharidae). Biological Journal of the Linnean Society 76: 303-314.

Lailvaux SP, Irschick DJ. 2006. A functional perspective on sexual selection: insights and future prospects. Animal Behaviour 72: 263-273.

Lailvaux SP, Herrel A, Vanhooydonck B, Meyers JJ, Irschick DJ. 2004. Performance capacity, fighting tactics, and the evolution of life-stage morphs in the green anole lizard (Anolis carolinensis). Proceedings of the Royal Society of London B 271: 2501-3508.

Lailvaux SP, Hathaway J, Pomfret J, Knell R. 2005. Horn size predicts physical performance in the beetle Euoniticellus intermedius (Coleoptera: Scarabaeidae). Functional Ecology 19: 632-639.

Lappin AK, Husak JF. 2005. Weapon performance, not size, determines mating success and potential reproductive output in the collared lizard, Crotaphytus collaris. American Naturalist 166: 426-436. 
Lobo F. 2001. A phylogenetic analysis of lizards of the Liolaernus chiliensis group (Iguania: Tropiduridae). Herpetological Journal 11: 137-150.

Lobo F. 2005. Las relaciones filogenéticas en el grupo chiliensis de Liolaemus (Iguania: Liolaemidae). Sumando nuevos caracteres y taxa. Acta Zoológica Lilloana 49: 6789.

Losos JB, Butler MA, Schoener TW. 2003. Sexual dimorphism in body size and shape in relation to habitat use among species of Caribbean Anolis lizards. In: Fox SF, McCoy JK, Baird TA, eds. Lizard social behavior. Baltimore: Johns Hopkins University Press, 356-380.

Meyers JJ, Herrel A. 2005. Prey capture kinematics of ant eating lizards. Journal of Experimental Biology 208: 113127.

Molina-Borja M, Padron-Fumero M, Alfonso-Martin MT. 1998. Morphological and behavioural traits affecting the intensity and outcome of male contests in Gallotia galloti galloti (Family Lacertidae). Ethology 104: 314-322.

O'Grady SP, Morando M, Avila L, Dearing MD. 2005. Correlating diet and digestive tract specialization: examples from the lizard family Liolaemidae. Zoology 108: 201-210.

Perry G, Levering K, Girard I, Garland T Jr. 2004. Locomotor performance and social dominance in male Anolis cristatellus. Animal Behaviour 67: 37-47.

Peterson CC, Husak JF. 2006. Locomotor performance and sexual selection: individual variation in sprint speed of collared lizards (Crotaphytus collaris). Copeia 2006: 216114.

Pincheira-Donoso D, Scolaro JA, Sura P. 2008. A monographic catalogue on the systematics and phylogeny of the South American iguanian lizard family Liolaemidae (Squamata, Iguania). Zootaxa 1800: 1-85.

Pincheira-Donoso D, Hodgson DJ, Stipala J, Tregenza T. 2009. A phylogenetic analysis of sex-specific evolution of ecological morphology in Liolaemus lizards. Ecological Research 24: 1223-1231.

Rocha CFD. 1999. Home range of the tropidurid lizard Liolaemus lutzae: sexual and body size differences. Revista Brasileira de Biologia 59: 125-130.

Schoener TW. 1967. Ecological significance of sexual dimorphism in size in the lizard Anolis conspersus. Science 155: $474-476$.
Schulte JA, Macey JR, Espinoza RE, Larson A. 2000. Phylogenetic relationships in the iguanid lizard genus Liolaemus: multiple origins of viviparous reproduction and evidence for recurring Andean vicariance and dispersal. Biological Journal of the Linnean Society 69: 75-102.

Schulte JA, Losos JB, Cruz FB, Núñez H. 2004. The relationship between morphology, escape behaviour and microhabitat occupation in the lizard clade Liolaemus (Iguanidae: Tropidurinae: Liolaemini). Journal of Evolutionary Biology 17: 408-420.

Selander RK. 1966. Sexual dimorphism and differential niche utilization in birds. Condor 68: 113-151.

Stuart-Fox DM, Moussalli A. 2007. Sex-specific ecomorphological variation and the evolution of sexual dimorphism in dwarf chameleons. Journal of Evolutionary Biology 20: 1073-1081.

Stuart-Fox DM, Ord TJ. 2004. Sexual selection, natural selection and the evolution of dimorphic coloration and ornamentation in agamid lizards. Proceedings of the Royal Society of London B 271: 2249-2255.

Tulli MJ, Cruz FB, Herrel A, Vanhooydonck B, Abdala V. 2009. The interplay between claw morphology and microhabitat use in Neotropical Iguanian lizards. Zoology 112: 379-392.

Van Damme R. 1999. Evolution of herbivory in lacertid lizards: effects of insularity and body size. Journal of Herpetology 33: 663-674.

Vanhooydonck B, Herrel A, Van Damme R, Irschick DJ. 2006. The quick and the fast: the evolution of acceleration capacity in Anolis lizards. Evolution 60: 2137-2147.

Vanhooydonck B, Herrel A, Van Damme R. 2007. Interactions between habitat use, behavior, and the trophic niche of lacertid lizards. In: Reilly SM, McBrayer LB, Miles DB, eds. Lizard ecology. Cambridge: Cambridge University Press, 427-449.

Verwaijen D, Van Damme R, Herrel A. 2002. Relationships between head size, bite force, prey handling efficiency and diet in two sympatric lacertid lizards. Functional Ecology 16: $842-850$.

Wilson RS, Franklin CE, James RS. 2000. Allometric scaling relationships of jumping performance in the striped marsh frog Limnodynastes peronii. Journal of Experimental Biology 203: 1937-1946. 


\section{APPENDIX 1}

Means and standard errors per species and $\operatorname{sex}(\mathrm{M}=$ males, $\mathrm{F}=$ females $)$ for all morphological variables and bite force measured in 19 species of Liolaemus. Morphological measurements are expressed in $\mathrm{mm}$, bite force is quoted in N. See text for abbreviations.

\begin{tabular}{|c|c|c|c|c|c|c|c|c|c|c|c|}
\hline Species & Sex & SVL & HL & HW & $\mathrm{HH}$ & LJL & $\mathrm{JO}$ & $\mathrm{CT}$ & $\begin{array}{l}\text { Inlever } \\
\text { opening }\end{array}$ & $\begin{array}{l}\text { Inlever } \\
\text { closing }\end{array}$ & Bite force \\
\hline Liolaemus & M & $85.17 \pm 5.87$ & $18.43 \pm 1.14$ & $12.46 \pm 0.93$ & $7.73 \pm 0.58$ & $19.27 \pm 1.24$ & $17.93 \pm 1.03$ & $13.60 \pm 0.79$ & $1.34 \pm 0.32$ & $4.33 \pm 0.31$ & $12.99 \pm 1.63$ \\
\hline baguali & $\mathrm{F}$ & $81.79 \pm 2.65$ & $15.90 \pm 0.25$ & $10.98 \pm 0.57$ & $7.13 \pm 0.68$ & $16.66 \pm 0.21$ & $16.15 \pm 0.22$ & $12.19 \pm 0.05$ & $0.52 \pm 0.01$ & $4.00 \pm 0.27$ & $10.40 \pm 1.77$ \\
\hline Liolaemus & M & $53.87 \pm 1.39$ & $11.69 \pm 0.22$ & $7.64 \pm 0.32$ & $5.45 \pm 0.24$ & $11.71 \pm 0.22$ & $11.14 \pm 0.20$ & $8.66 \pm 0.19$ & $0.58 \pm 0.18$ & $2.47 \pm 0.07$ & $3.27 \pm 0.27$ \\
\hline bibroni & $\mathrm{F}$ & $55.98 \pm 1.53$ & $11.38 \pm 0.22$ & $7.81 \pm 0.23$ & $5.43 \pm 0.14$ & $11.52 \pm 0.17$ & $10.81 \pm 0.25$ & $8.87 \pm 0.19$ & $0.71 \pm 0.10$ & $1.93 \pm 0.07$ & $2.46 \pm 0.30$ \\
\hline Liolaemus & M & $94.81 \pm 2.40$ & $18.63 \pm 0.42$ & $11.27 \pm 0.53$ & $9.50 \pm 0.15$ & $19.62 \pm 0.52$ & $18.29 \pm 0.35$ & $14.06 \pm 0.26$ & $1.33 \pm 0.20$ & $4.22 \pm 0.12$ & $14.14 \pm 1.01$ \\
\hline canqueli & $\mathrm{F}$ & $88.70 \pm 2.15$ & $17.04 \pm 0.46$ & $11.27 \pm 0.53$ & $8.02 \pm 0.31$ & $17.77 \pm 0.47$ & $16.33 \pm 0.36$ & $12.94 \pm 0.29$ & $1.44 \pm 0.15$ & $3.39 \pm 0.09$ & $10.95 \pm 1.21$ \\
\hline Liolaemus & M & $78.17 \pm 2.58$ & $16.64 \pm 0.56$ & $12.38 \pm 0.42$ & $7.89 \pm 0.53$ & $17.03 \pm 0.61$ & $16.16 \pm 0.51$ & $12.61 \pm 0.29$ & $0.86 \pm 0.11$ & $3.55 \pm 0.40$ & $8.32 \pm 0.79$ \\
\hline$c e i$ & $\mathrm{~F}$ & $76.39 \pm 1.64$ & $16.11 \pm 0.19$ & $11.47 \pm 0.22$ & $7.25 \pm 0.14$ & $16.54 \pm 0.40$ & $15.56 \pm 0.31$ & $12.35 \pm 0.21$ & $0.98 \pm 0.10$ & $3.21 \pm 0.20$ & $5.62 \pm 0.38$ \\
\hline Liolaemus & M & $61.69 \pm 0.82$ & $12.89 \pm 0.16$ & $9.34 \pm 0.17$ & $5.81 \pm 0.12$ & $13.49 \pm 0.15$ & $12.57 \pm 0.16$ & $10.12 \pm 0.15$ & $0.92 \pm 0.09$ & $2.45 \pm 0.10$ & $5.08 \pm 0.36$ \\
\hline coeruleus & $\mathrm{F}$ & $63.27 \pm 1.15$ & $12.41 \pm 0.23$ & $9.09 \pm 0.23$ & $5.60 \pm 0.20$ & $12.91 \pm 0.33$ & $11.91 \pm 0.32$ & $9.64 \pm 0.25$ & $1.00 \pm 0.12$ & $2.27 \pm 0.11$ & $3.64 \pm 0.44$ \\
\hline Liolaemus & M & $74.84 \pm 1.79$ & $16.27 \pm 0.34$ & $10.53 \pm 0.21$ & $6.82 \pm 0.12$ & $16.31 \pm 0.32$ & $15.66 \pm 0.29$ & $12.19 \pm 0.27$ & $0.64 \pm 0.12$ & $3.47 \pm 0.09$ & $8.57 \pm 0.60$ \\
\hline elongatus & $\mathrm{F}$ & $63.13 \pm 2.18$ & $13.99 \pm 0.37$ & $8.94 \pm 0.23$ & $5.88 \pm 0.14$ & $14.11 \pm 0.40$ & $13.51 \pm 0.37$ & $10.79 \pm 0.25$ & $0.60 \pm 0.10$ & $2.72 \pm 0.12$ & $6.19 \pm 0.54$ \\
\hline Liolaemus & M & $79.64 \pm 1.30$ & $17.27 \pm 0.17$ & $11.22 \pm 0.18$ & $8.95 \pm 0.66$ & $18.01 \pm 0.52$ & $16.65 \pm 0.33$ & $12.99 \pm 0.31$ & $1.37 \pm 0.29$ & $3.66 \pm 0.16$ & $10.41 \pm 1.17$ \\
\hline escachardosi & $\mathrm{F}$ & $68.29 \pm 0.91$ & $14.34 \pm 0.49$ & $8.81 \pm 0.44$ & $6.00 \pm 0.02$ & $14.48 \pm 0.52$ & $13.36 \pm 0.04$ & $10.47 \pm 0.42$ & $1.12 \pm 0.48$ & $2.89 \pm 0.38$ & $4.88 \pm 0.00$ \\
\hline Liolaemus & M & $93.55 \pm 3.50$ & $18.66 \pm 0.80$ & $12.76 \pm 0.78$ & $9.18 \pm 0.60$ & $19.39 \pm 0.78$ & $18.11 \pm 0.63$ & $14.21 \pm 0.73$ & $1.28 \pm 0.32$ & $3.90 \pm 0.19$ & $14.27 \pm 2.42$ \\
\hline fitzingeri & $\mathrm{F}$ & $89.92 \pm 2.44$ & $17.78 \pm 0.37$ & $11.46 \pm 0.27$ & $8.15 \pm 0.24$ & $17.93 \pm 0.44$ & $16.72 \pm 0.34$ & $13.33 \pm 0.23$ & $1.21 \pm 0.21$ & $3.39 \pm 0.16$ & $10.70 \pm 0.56$ \\
\hline Liolaemus & M & $59.18 \pm 1.13$ & $12.91 \pm 0.21$ & $9.18 \pm 0.25$ & $5.68 \pm 0.22$ & $13.12 \pm 0.26$ & $12.32 \pm 0.27$ & $9.36 \pm 0.20$ & $0.80 \pm 0.12$ & $2.96 \pm 0.16$ & $3.89 \pm 0.31$ \\
\hline hatcheri & $\mathrm{F}$ & $59.17 \pm 0.26$ & $11.61 \pm 0.16$ & $8.59 \pm 0.14$ & $5.29 \pm 0.09$ & $11.97 \pm 0.15$ & $11.28 \pm 0.14$ & $8.60 \pm 0.12$ & $0.69 \pm 0.11$ & $2.68 \pm 0.09$ & $2.63 \pm 0.12$ \\
\hline Liolaemus & M & $73.78 \pm 2.41$ & $15.71 \pm 0.17$ & $10.57 \pm 0.49$ & $7.64 \pm 0.31$ & $16.19 \pm 0.19$ & $15.53 \pm 0.23$ & $11.77 \pm 0.17$ & $0.66 \pm 0.05$ & $3.76 \pm 0.24$ & $8.95 \pm 0.91$ \\
\hline kingii & $\mathrm{F}$ & $74.98 \pm 2.41$ & $14.94 \pm 0.38$ & $10.01 \pm 0.18$ & $6.91 \pm 0.19$ & $15.56 \pm 0.34$ & $14.59 \pm 0.30$ & $11.25 \pm 0.22$ & $0.97 \pm 0.09$ & $3.34 \pm 0.11$ & $8.53 \pm 0.50$ \\
\hline Liolaemus & M & $55.53 \pm 1.26$ & $12.02 \pm 0.27$ & $8.85 \pm 0.25$ & $5.40 \pm 0.21$ & $12.64 \pm 0.26$ & $11.89 \pm 0.23$ & $9.12 \pm 0.26$ & $0.75 \pm 0.12$ & $2.77 \pm 0.10$ & $2.58 \pm 0.30$ \\
\hline kolengh & $\mathrm{F}$ & $56.66 \pm 0.88$ & $11.70 \pm 0.21$ & $8.45 \pm 0.15$ & $5.16 \pm 0.10$ & $11.71 \pm 0.18$ & $11.10 \pm 0.17$ & $8.59 \pm 0.21$ & $0.61 \pm 0.19$ & $2.51 \pm 0.14$ & $2.35 \pm 0.17$ \\
\hline Liolaemus & M & $78.96 \pm 1.42$ & $16.50 \pm 0.22$ & $11.65 \pm 0.18$ & $8.61 \pm 0.20$ & $17.22 \pm 0.23$ & $16.26 \pm 0.24$ & $12.75 \pm 0.21$ & $0.95 \pm 0.12$ & $3.52 \pm 0.08$ & $10.57 \pm 0.78$ \\
\hline mapuche & $\mathrm{F}$ & $71.01 \pm 2.02$ & $14.18 \pm 0.24$ & $9.95 \pm 0.12$ & $7.32 \pm 0.28$ & $14.62 \pm 0.26$ & $14.11 \pm 0.32$ & $11.08 \pm 0.30$ & $0.51 \pm 0.15$ & $3.03 \pm 0.07$ & $6.49 \pm 0.66$ \\
\hline Liolaemus & M & $67.23 \pm 0.69$ & $14.53 \pm 0.14$ & $10.04 \pm 0.17$ & $7.09 \pm 0.07$ & $14.79 \pm 0.19$ & $14.33 \pm 0.14$ & $10.87 \pm 0.07$ & $0.47 \pm 0.09$ & $3.46 \pm 0.11$ & $8.92 \pm 0.49$ \\
\hline morenoi & $\mathrm{F}$ & $69.03 \pm 1.29$ & $14.22 \pm 0.20$ & $9.92 \pm 0.16$ & $7.05 \pm 0.06$ & $14.48 \pm 0.24$ & $13.80 \pm 0.22$ & $10.80 \pm 0.15$ & $0.68 \pm 0.08$ & $3.00 \pm 0.16$ & $9.09 \pm 0.36$ \\
\hline Liolaemus & M & $90.63 \pm 3.76$ & $19.87 \pm 1.47$ & $13.31 \pm 0.73$ & $7.93 \pm 0.41$ & $21.50 \pm 1.49$ & $20.00 \pm 01.68$ & $15.43 \pm 0.71$ & $1.50 \pm 0.19$ & $4.57 \pm 0.97$ & $10.53 \pm 0.00$ \\
\hline petrophilus & $\mathrm{F}$ & $78.46 \pm 2.65$ & $17.89 \pm 0.48$ & $11.22 \pm 0.39$ & $6.79 \pm 0.34$ & $18.42 \pm 0.60$ & $17.21 \pm 0.57$ & $13.68 \pm 0.44$ & $1.21 \pm 0.17$ & $3.53 \pm 0.20$ & $6.77 \pm 1.02$ \\
\hline Liolaemus & M & $79.35 \pm 4.88$ & $16.55 \pm 0.63$ & $12.32 \pm 0.75$ & $8.48 \pm 0.34$ & $18.10 \pm 0.73$ & $16.49 \pm 0.91$ & $13.26 \pm 0.45$ & $1.61 \pm 0.22$ & $3.23 \pm 0.49$ & $5.76 \pm 0.66$ \\
\hline rothi & $\mathrm{F}$ & $80.90 \pm 6.78$ & $17.10 \pm 1.30$ & $12.33 \pm 1.18$ & $8.19 \pm 0.75$ & $18.47 \pm 1.41$ & $16.67 \pm 01.25$ & $13.07 \pm 0.93$ & $1.80 \pm 0.17$ & $3.59 \pm 0.32$ & $5.27 \pm 1.12$ \\
\hline Liolaemus & M & $72.81 \pm 3.55$ & $15.43 \pm 0.76$ & $10.50 \pm 0.68$ & $7.81 \pm 0.65$ & $16.34 \pm 0.85$ & $15.36 \pm 0.74$ & $11.76 \pm 0.57$ & $0.98 \pm 0.19$ & $3.60 \pm 0.32$ & $7.12 \pm 1.01$ \\
\hline sarmientoi & $\mathrm{F}$ & $74.70 \pm 0.21$ & $15.11 \pm 0.00$ & $10.11 \pm 0.29$ & $7.67 \pm 0.17$ & $15.95 \pm 0.01$ & $14.79 \pm 0.29$ & $11.70 \pm 0.29$ & $1.17 \pm 0.30$ & $3.09 \pm 0.00$ & $5.46 \pm 0.38$ \\
\hline Liolaemus & M & $53.03 \pm 2.16$ & $12.98 \pm 0.47$ & $8.62 \pm 0.35$ & $5.30 \pm 0.35$ & $13.44 \pm 0.56$ & $12.64 \pm 0.43$ & $10.00 \pm 0.34$ & $0.80 \pm 0.21$ & $2.64 \pm 0.22$ & $5.22 \pm 0.34$ \\
\hline tenuis & $\mathrm{F}$ & $51.91 \pm 2.73$ & $12.15 \pm 0.49$ & $7.34 \pm 0.22$ & $4.79 \pm 0.22$ & $12.04 \pm 0.44$ & $11.41 \pm 0.48$ & $9.02 \pm 0.32$ & $0.63 \pm 0.15$ & $2.38 \pm 0.15$ & $3.73 \pm 0.31$ \\
\hline Liolaemus & M & $82.39 \pm 3.78$ & $16.81 \pm 0.57$ & $11.39 \pm 0.52$ & $7.99 \pm 0.43$ & $17.30 \pm 0.58$ & $16.29 \pm 0.62$ & $12.64 \pm 0.44$ & $1.00 \pm 0.29$ & $3.65 \pm 0.21$ & $11.83 \pm 1.19$ \\
\hline xanthoviridis & $\mathrm{F}$ & $84.17 \pm 2.36$ & $16.84 \pm 0.49$ & $10.70 \pm 0.72$ & $7.73 \pm 0.62$ & $16.60 \pm 0.54$ & $15.90 \pm 0.65$ & $12.22 \pm 0.27$ & $0.70 \pm 0.11$ & $3.68 \pm 0.38$ & $10.27 \pm 0.64$ \\
\hline Liolaemus & $\mathrm{M}$ & $68.33 \pm 2.90$ & $15.95 \pm 0.48$ & $10.62 \pm 0.33$ & $7.75 \pm 0.28$ & $16.57 \pm 0.41$ & $15.73 \pm 0.43$ & $11.92 \pm 0.36$ & $0.84 \pm 0.32$ & $3.81 \pm 0.16$ & $7.83 \pm 0.81$ \\
\hline zullyi & $\mathrm{F}$ & $66.50 \pm 3.12$ & $14.03 \pm 0.78$ & $9.42 \pm 0.44$ & $6.94 \pm 0.33$ & $14.66 \pm 0.93$ & $13.94 \pm 0.90$ & $10.78 \pm 0.58$ & $0.72 \pm 0.07$ & $3.16 \pm 0.32$ & $4.86 \pm 0.61$ \\
\hline
\end{tabular}




\section{APPENDIX 2}

Number of faeces gathered per species, with number of items per prey type according to taxonomical classification. Ants, cockroaches, spiders, larvae, and fruits were classified as soft prey; grasshoppers and flowers were classified as intermediately hard prey; coleopterans and seeds were classified as hard prey on the 'hardness' scale. Ants, coleopterans, cockroaches, and grasshoppers were classified as evasive prey on the 'evasiveness' scale (cf. Vanhooydonck et al., 2007). Relative volumes were expressed in ant volume units (see text for more details).

\begin{tabular}{|c|c|c|c|c|c|c|c|c|c|c|}
\hline \multirow[b]{2}{*}{ Species } & \multirow{2}{*}{$\begin{array}{l}\text { No. of } \\
\text { faeces }\end{array}$} & \multicolumn{6}{|c|}{ Animal prey } & \multicolumn{3}{|c|}{ Plant material } \\
\hline & & Ants & Coleopterans & Cockroaches & Grasshoppers & Larvae & Spiders & Flowers & Fruits & Seeds \\
\hline Liolaemus baguali & 40 & 6 & 3 & 0 & 0 & 0 & 0 & 32 & 19 & 0 \\
\hline Liolaemus bibroni & 22 & 98 & 0 & 0 & 0 & 0 & 0 & 5 & 0 & 0 \\
\hline Liolaemus canqueli & 15 & 5 & 0 & 0 & 0 & 0 & 0 & 11 & 6 & 0 \\
\hline Liolaemus ceii & 11 & 0 & 0 & 0 & 0 & 0 & 0 & 11 & 0 & 0 \\
\hline Liolaemus coeruleus & 34 & 87 & 0 & 0 & 0 & 0 & 0 & 23 & 0 & 0 \\
\hline Liolaemus elongatus & 22 & 108 & 0 & 0 & 0 & 0 & 0 & 3 & 0 & 0 \\
\hline Liolaemus escachardosi & 42 & 8 & 5 & 0 & 0 & 0 & 0 & 31 & 0 & 11 \\
\hline Liolaemus fitzingeri & 106 & 21 & 3 & 1 & 0 & 0 & 0 & 45 & 0 & 104 \\
\hline Liolaemus hatcheri & 29 & 0 & 14 & 0 & 2 & 0 & 0 & 9 & 14 & 22 \\
\hline Liolaemus kingii & 61 & 16 & 10 & 0 & 0 & 0 & 0 & 57 & 12 & 0 \\
\hline Liolaemus kolengh & 46 & 19 & 9 & 0 & 0 & 0 & 0 & 38 & 1 & 0 \\
\hline Liolaemus mapuche & 12 & 86 & 0 & 0 & 0 & 0 & 0 & 3 & 0 & 0 \\
\hline Liolaemus morenoi & 10 & 99 & 0 & 0 & 0 & 0 & 0 & 0 & 0 & 1 \\
\hline Liolaemus petrophilus & 30 & 98 & 0 & 0 & 0 & 0 & 0 & 3 & 0 & 0 \\
\hline Liolaemus rothi & 8 & 41 & 0 & 0 & 0 & 0 & 0 & 7 & 0 & 0 \\
\hline Liolaemus sarmientoi & 30 & 9 & 3 & 0 & 0 & 0 & 0 & 28 & 0 & 0 \\
\hline Liolaemus tenuis & 21 & 60 & 0 & 0 & 0 & 0 & 0 & 8 & 0 & 0 \\
\hline Liolaemus xanthoviridis & 14 & 6 & 0 & 0 & 0 & 0 & 0 & 11 & 1 & 0 \\
\hline Liolaemus zullyi & 44 & 10 & 11 & 0 & 1 & 6 & 1 & 34 & 0 & 0 \\
\hline
\end{tabular}

